Int. J. Dev. Biol. 48: 637-643 (2004)

doi: $10.1387 / \mathrm{ijdb} .0317781 \mathrm{w}$

Original Article

\title{
Effects of FGF9 on embryonic Sertoli cell proliferation and testicular cord formation in the mouse
}

\author{
LOUISE WILLERTON, ROBERT A. SMITH, DAVID RUSSELL and SARAH MACKAY* \\ Sertoli Cell Group, Division of Neuroscience and Biomedical Systems, Institute of Biomedical and Life Sciences, \\ University of Glasgow, Glasgow, Scotland.
}

\begin{abstract}
Proliferation and cord formation by embryonic Sertoli cells are pivotal events involved in testis morphogenesis. A number of growth factors have been implicated in mediating these events. However, the exact level of involvement and importance of each as yet remains elusive. We have adopted an in vitro approach to assess developing mouse Sertoli cells, whereby they are cultured in the presence or absence of fibroblast growth factor (FGF9) and/or extracellular matrix (ECM) gel, since previous studies have shown that ECM gel aids Sertoli cell differentiation. The present findings corroborate this effect, but in addition demonstrate that in the presence of FGF9 $(10 \mathrm{ng} / \mathrm{ml})$, cells undergo greater proliferation than those cultured on gel alone. They also display a differentiated epithelial phenotype, with appositional contact of cell membranes in cord-like aggregations. In addition we have shown that cultured Sertoli cells generally express a smaller truncated, nuclear form of the FGFr3, although in the presence of FGF9 and absence of gel, the larger, cytoplasmic form of the receptor is also expressed. Immunolocalisation of FGFr3 in Sertoli cells of whole testes revealed a temporal expression pattern profile, with high levels being abundant in the embryonic testicular cords and at puberty, but an absence in adult Sertoli cells. Our findings suggest that FGF9 plays an important role in proliferation and organisation of embryonic Sertoli cells during testis morphogenesis.
\end{abstract}

KEY WORDS: Sertoli cell, FGF9, cell culture, gonadal differentiation, testicular cord

\section{Introduction}

Many factors contribute to male infertility. Some disorders of testicular function may arise due to abnormal organisation or proliferation of the embryonic Sertoli cells (reviewed by Sharpe et al., 2003), which can result in cellular dysfunction, defective morphology and reduced cell number. Sertoli cells play a pivotal role in testis morphogenesis as they are the first cell type to differentiate, an event which enables seminiferous cord formation. Germ cell entry into meiosis is prevented as the embryonic Sertoli cells aggregate and enclose the newly arrived germ cells (reviewed by Mackay 2000). There is a significant relationship between the number of Sertoli cells and sperm density, thus more Sertoli cells means numerically the potential for greater sperm production (Orth et al., 1988; Sharpe 1994, 1999). Proliferation of the Sertoli cells during development therefore is vital for normal adult fertility.

Specification and commitment of a bipotential gonad to differentiate into a testis is dependent on the occurrence of time-specific key events at both the molecular and cellular level. The discovery of the testis-determining gene, Sry, in the 1990s has directed attention to the Sertoli cells, since Sry appears to act in a cellautonomous fashion. Development diverges when it is expressed during a narrow window of time, between embryonic day (E)10.512.5 in the mouse $X Y$ gonad. $S R Y$ initiates several other downstream targets, including Sox9, another transcription factor, which is also expressed in the Sertoli cells (reviewed by Swain and LovellBadge 1999). Upon induction by Sry, a cascade of molecular signalling occurs, resulting in the male pathway of development.

\footnotetext{
Abbreviations used in this paper: $\mathrm{AMH}$, anti-Müllerian hormone; DAB, diaminobenzidine; DMEM, Dulbecco's Modified Eagle's Medium; DPC, days post coitum; E, embryonic; ECM, extracellular matrix; EGF, epidermal growth factor; FGF9, fibroblast growth factor 9; FGFr3, fibroblast growth factor receptor 3; FSH, follicle stimulating hormone; GDNF, glial-derived neurotrophic factor; ICC, immunocytochemistry; NT3, neurotrophin 3; PBS, phosphate buffered saline; PCNA, proliferating cell nuclear antigen; PCR, polymerase chain reaction; PDGF, platelet derived growth factor; SRY, sex determining region of the Y chromosome; TGF $\beta$, transforming growth factor beta.
} 

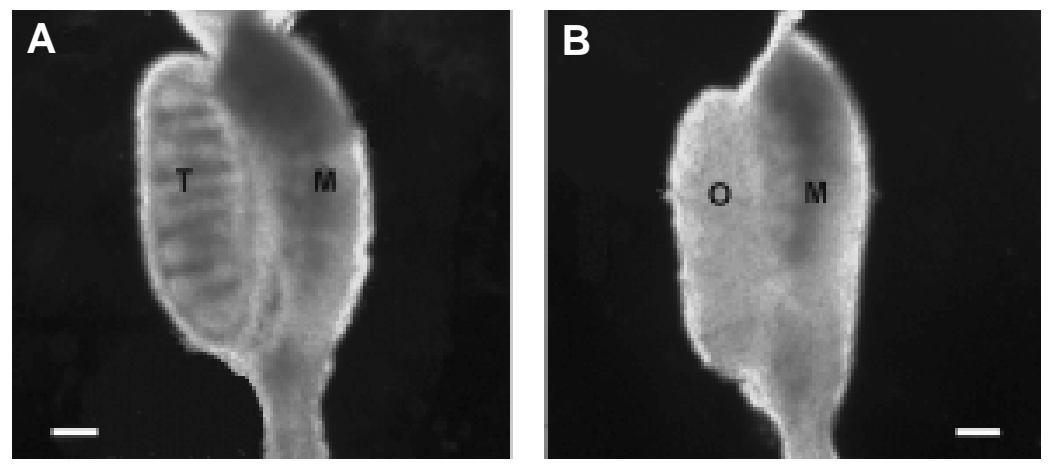

Fig. 1. E14.5 urogenital complexes as removed from embryos. (A) Male complex showing mesonephros (M) and testis (T) with striped appearance resulting from testis cords. (B) Female complex including mesonephros (M) and ovary (O) with homogenous granular appearance. Bars, $200 \mu \mathrm{m}$

Increased cellular proliferation is triggered by Sry expression. This is a crucial step in testis morphogenesis and is critical for establishment of the male differentiation pathway. The increased proliferation occurs within an 8 hour time window whereby the male gonad doubles its size relative to the female (Schmahl et al., 2000; Schmahl and Capel 2003). One of the first morphologically distinct events in testis development is the aggregation and rearrangement of pre-Sertoli cells and germ cells to form cords (Pelliniemi et al., 1993). As the cords mature they become surrounded by peritubular myoid cells, which migrate into the gonad from the mesonephros from around E11.5 in the mouse (Buehr et al., 1993). These cells interact with the Sertoli cells and a basement membrane is formed between the two cell types (Tung and Fritz 1980; Skinner etal.1985). Many factors, involved in signalling pathways downstream of Sry, have been implicated in controlling the processes of cell migration, proliferation and differentiation and underlie mammalian gonadal development (see Mackay 2000). An important early signal in the developing testis, prostaglandin $\mathrm{D} 2$, is produced by the primordial germ cells and has been proposed to act as a paracrine factor to induce Sertoli cell differentiation (Adams and McLaren 2002).

Upon commitment of the somatic cells to the Sertoli cell line, cord formation proceeds. Several mediating factors are proposed to have a role in this event. One study has implicated platelet-derived growth factor (PDGF) as being a regulatory candidate. This hypothesis was tested by Uzumcu et al., (2002), who cultured E13 rat testes in the presence of a PDGF inhibitor (tyrphostin), demonstrating that inhibition of PDGF action did not prevent cord formation but altered normal cord development and morphology (Uzumcu et al., 2002). Tyrphostin-treated testes formed «swollen cords". This phenomenon tends to occur when there is a significant decrease in the number of cords per testis area and increased cord diameter due to fusion of cords. Platelet-derived growth
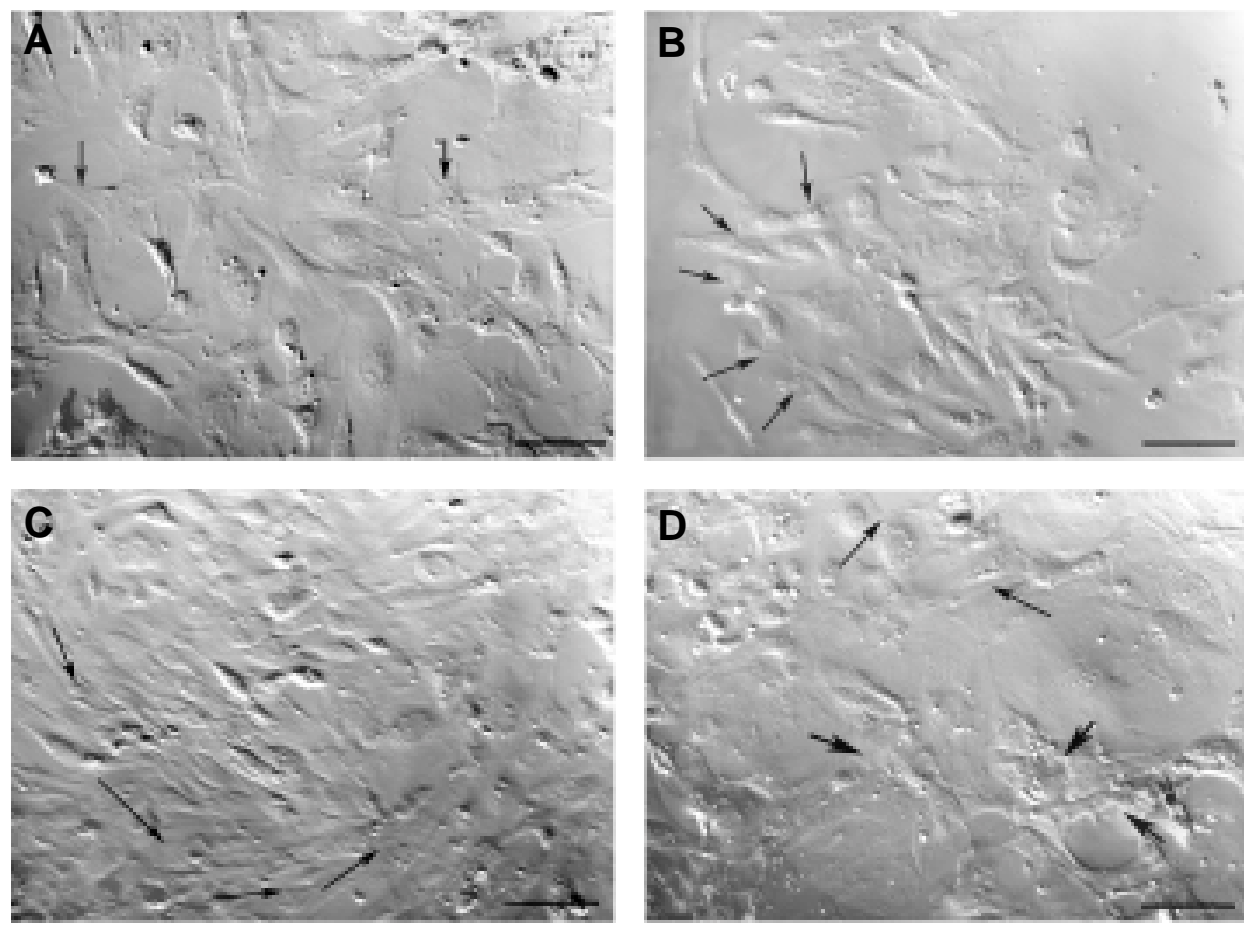

Fig. 2. E14.5 Sertoli cells after $\mathbf{7 2} \mathbf{h}$ culture. (A) Control without addition of either FGF9 or ECM gel; arrows denote stellate mesenchymal appearance of cells. (B) Cells cultured on ECM gel substrate, but in the absence of FGF9. Arrows indicate outlines of cord-like aggregations of cells. Note well-apposed membranes between neighbouring cells. (C) Culture including $10 \mathrm{ng} / \mathrm{ml} \mathrm{FGF9} \mathrm{but} \mathrm{without} \mathrm{ECM} \mathrm{gel.}$ Arrows denote directional growth of cells. (D) Culture with both ECM gel and $10 \mathrm{ng} / \mathrm{ml} \mathrm{FGF9}$. Small arrows denote apposition of cell membranes of neighbouring cells; large arrows denote outline of cordlike aggregations. Bars, $100 \mu \mathrm{m}$. 

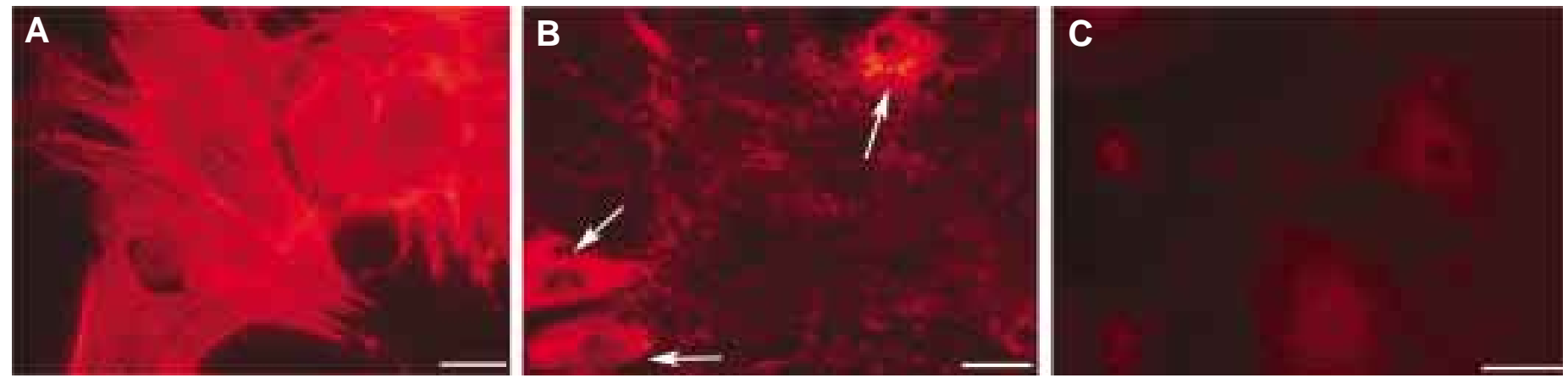

Fig. 3. (A) Fluorescent immunostaining of peritubular cell marker, smooth muscle $\alpha$-actin, in cells cultured from supernatant of isolation protocol. (B) E14.5 Sertoli cells cultured for 4 days on ECM gel show positive staining for anti-Müllerian hormone. (C) Negative staining control without anti-Müllerian hormone primary antibody. Bar, $20 \mu \mathrm{m}(A), 50 \mu m(B, C)$.

identified members. They are intercellular signalling molecules with multiple and varied roles in animal development. (Burgess and Maciag 1989; Crumley et al., 1991). Knockout mice studies demonstrated that in the absence of FGF9, gonadal development is directed along the female pathway of differentiation. This occurred in the majority of $\mathrm{XY}$ individuals, although a few animals did display male traits in the form of hypoplastic testes (Colvin et al., 2001). The specific role of FGF9 in Sertoli cell proliferation, organisation and differentiation however remains elusive (Adams and McLaren 2002); therefore, an in vitro approach has been utilised in the present study, to determine more fully the effect of FGF9 on isolated developing Sertoli cells in culture.

\section{Results}

\section{Phase contrast microscope observations}

In all experimental regimes (i.e. in the presence of FGF9 and /or ECM gel) the embryonic Sertoli cells displayed flattening and attachment to substrate after $24 \mathrm{hrs}$ in culture. In the control wells (i.e. DMEM only), cells proliferated, but possessed a mesenchymal morphology (larger, stellate and with more cytoplasmic processes), indicative of an undifferentiated state (Fig. 2A). The cells cultured on ECM gel without growth factor assumed an epitheliallike phenotype (Mackay et al., 1999) and clustered together, with close apposition of neighbouring cell membranes, to form cordlike structures (Fig. 2 B,D). Cells cultured with FGF9 in absence of gel demonstrated rapid proliferation after $48 \mathrm{hrs}$ in culture compared to the other wells (Fig. 2C). The cells in experimental wells containing both gel and FGF9 began to form cord-like aggregations after $48 \mathrm{hrs}$, which were abundant after 4 days.

\section{Monitoring of isolation procedure}

Investigations of the cultures of supernatants revealed that germ cells were largely removed in the first centrifugation, while fibroblasts, interstitial cells and peritubular myoid cells (Fig. 3A) were contained in subsequent supernatants. Sertoli cells, as identified by granular-like immunostaining of $\mathrm{AMH}$ in the cytoplasm (Fig. 3B), were found in the cultures prepared from the final pellet of the isolation procedure. No signal was detected in negative controls lacking the AMH primary antibody (Fig. 3C).

\section{PCNA expression in cultured embryonic Sertoli cells}

Mitotic cells with PCNA immuno-positive nuclei were present in control and experimental wells (Fig. 4A). Significantly more PCNA-positive cells were present in cultures supplemented with FGF9 compared to controls in medium alone (Fig. 4 B,C) at the two time points assessed ( 3 and 7 days).

\section{FGFr3 expression in cultured embryonic Sertoli cells}

Negative ICC staining controls lacking primary antibody demonstrated little immunoreactivity (Fig. 5A). Immunolocalisation of FGFr3 was detectable in cells from all culture regimes (Fig. 5 B-
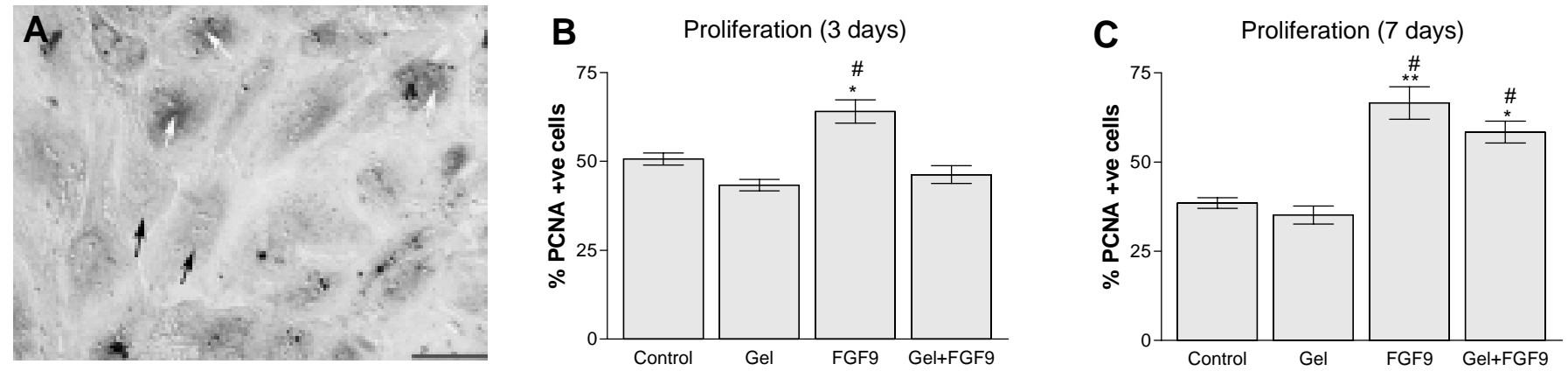

Fig. 4. (A) Immunolocalisation of PCNA in E14.5 Sertoli cells cultured for 7 days. White arrows highlight representative positively stained cells, whilst black arrows indicate negatively stained cells. Bar, $50 \mu \mathrm{m}$. (B,C) Histograms show percentages of PCNA positive cells in control (without ECM gel or FGF9) and experimental cultures after 3 and 7 days respectively. Data analysed using Kruskall Wallis and Dunns multiple comparison Post hoc analysis. ${ }^{*}$, significantly different $(P<0.05)$ from control without ECM gel. ${ }^{* *},(P<0.01)$. \#, significantly different from ECM gel alone $(P<0.05)$. 

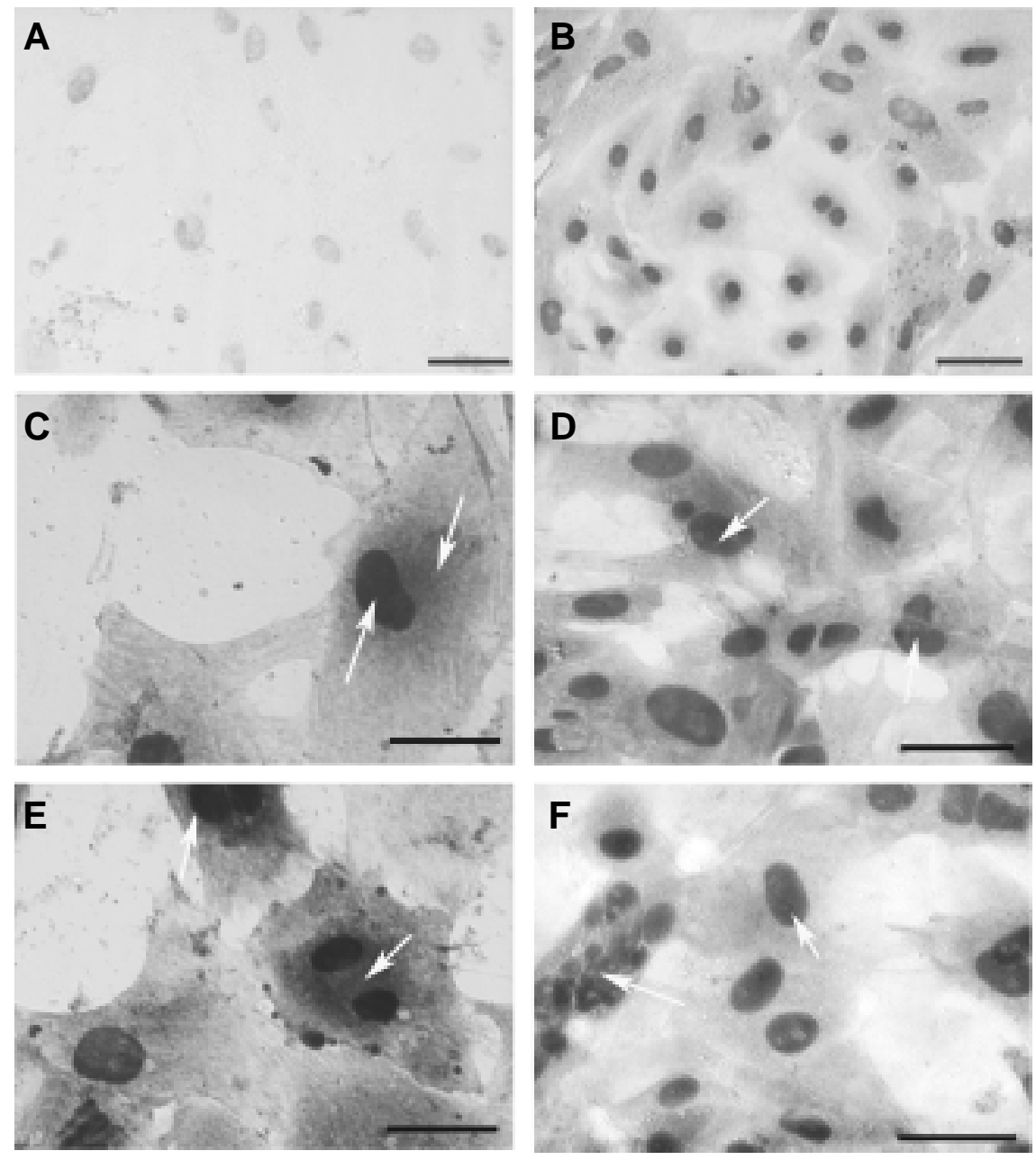

Fig. 5. FGFr3 expression in E14.5 Sertoli cells cultured for 7 days. (A) Negative staining control lacking primary antibody to FGFr3 in a culture without ECM gel or FGF9. (B) Sertoli cells cultured in absence of both ECM gel and FGF9 show immunostaining for FGFr3. (C) High power view of Sertoli cells cultured without ECM gel or FGF9 shows staining to be both nuclear and cytoplasmic (arrows). (D) In cells cultured on ECM gel without added FGF9, immunostaining is predominantly nuclear (arrows). (E) Both nuclear and cytoplasmic staining (arrows) was evident in cells cultured with $10 \mathrm{ng} / \mathrm{ml}$ FGF9 on uncoated substrate. (F) Arrows indicate both nuclear and cytoplasmic staining in cells cultured on ECM gel and in the presence of $10 \mathrm{ng} / \mathrm{ml}$ FGF9. Bars, $50 \mu \mathrm{m}(A, B) ; 20 \mu \mathrm{m}(C-F)$.

F); however, in the presence of FGF9 more positively-stained cells were apparent. Staining was predominantly nuclear but, in the absence of ECM gel, cytoplasmic staining was also observed (Fig. 5 C,E).

\section{FGFr3 expression in the testes in vivo}

FGFr3 expression was detected in the testicular cords of the E14.5 urogenital complex, but was absent from testicular interstitial tissue and from the mesonephros and metanephros (Fig. 6A). All the cell types of the seminiferous tubules of postnatal Day 15 testes showed abundant FGFr3 staining (Fig. 6B). By Day 25 expression was more localised to the spermatagonia and spermatocytes (Fig. 6C), while in the adult expression was restricted to the spermatogonia (Fig. 6D). FGFr3expression was absent in the interstitial compartment of the testes of all ages and in the staining control without primary antibody (Fig. 6E).

\section{Discussion}

It is widely accepted that proliferation and aggregation of somatic cells during development are crucial events in establishing the fate of the gonad, committing it to form a testis (Schmahl and Capel 2003). In the current study we have demonstrated that addition of FGF9 to embryonic Sertoli cells in culture induces enhanced proliferation with an approximately two-fold increase in cell number after 7 days with exogenous FGF9 in the absence of gel. Cells cultured on ECM gel formed cord-like aggregations, displaying an epitheliallike phenotype. These observations are consistent with our previous findings that ECM gel enhances cord-like aggregation and morphological maturation of the embryonic Sertoli cells in culture (Mackay et al., 1999). Functional maturity of the cultured Sertoli cells was confirmed by immunocytochemistry for the presence of AMH (Mackay et al., 2004).

The presence of FGF9 and ECM gel together increased proliferation and induced cord-like aggregation of the developing Sertoli cells. Control cells in DMEM alone however, remained randomly distributed with only minor aggregations, despite attaching and showing proliferation. These results support our previous findings that ECM gel promotes maturation of an epithelial-like phenotype (Mackay et al., 1999). Extra-cellular matrix is known to have an inductive effect on epithelial cells via integrin signalling (reviewed by Giancotti and Ruoslahti 1999). Our findings for the effect of FGF9 are also consistent with those of Colvin and co-workers (2001), who found that functional testes were absent in the FGF9 knock-out mouse demonstrating the key role of the growth factor in embryonic testis cord morphogenesis.

Fibroblast growth factor receptor 3 localisation was detected predominantly in the nucleus of all the cultured cells, with some cytoplasmic staining apparent in control cultures without FGF9 and those with FGF9 alone. At first sight this might appear counter-intuitive, since FGFr3 is a transmembrane receptor. However, other studies have shown that FGFr3 exists in two forms, which are generated via alternate splicing: the smaller transcript is expressed predominantly in epithelial cells and the larger one in fibroblasts (Scotet and Houssaint 1995). In addition the smaller transcript is reported to be localised in the nucleus of epithelial cells, whereas the larger form is generally located in the cytoplasm (Johnston et al., 1995). Positive localisation of FGFr3 in cultured embryonic Sertoli cells strengthens further the proposal that FGF9 has an important organisational role in the supporting cell lineage. The addition of FGF9 in the absence of ECM gel, may induce an up-regulation of FGFr3 as found for FGFr1 expression levels in cultured developing rat brain oligodendrocytes (Cohen and Chandross 2000). Furthermore, exposure of human fibroblasts to epidermal growth factor (EGF) has been shown to upregulate transforming growth factor beta (TGF $\beta$ ) receptor (Yamane 

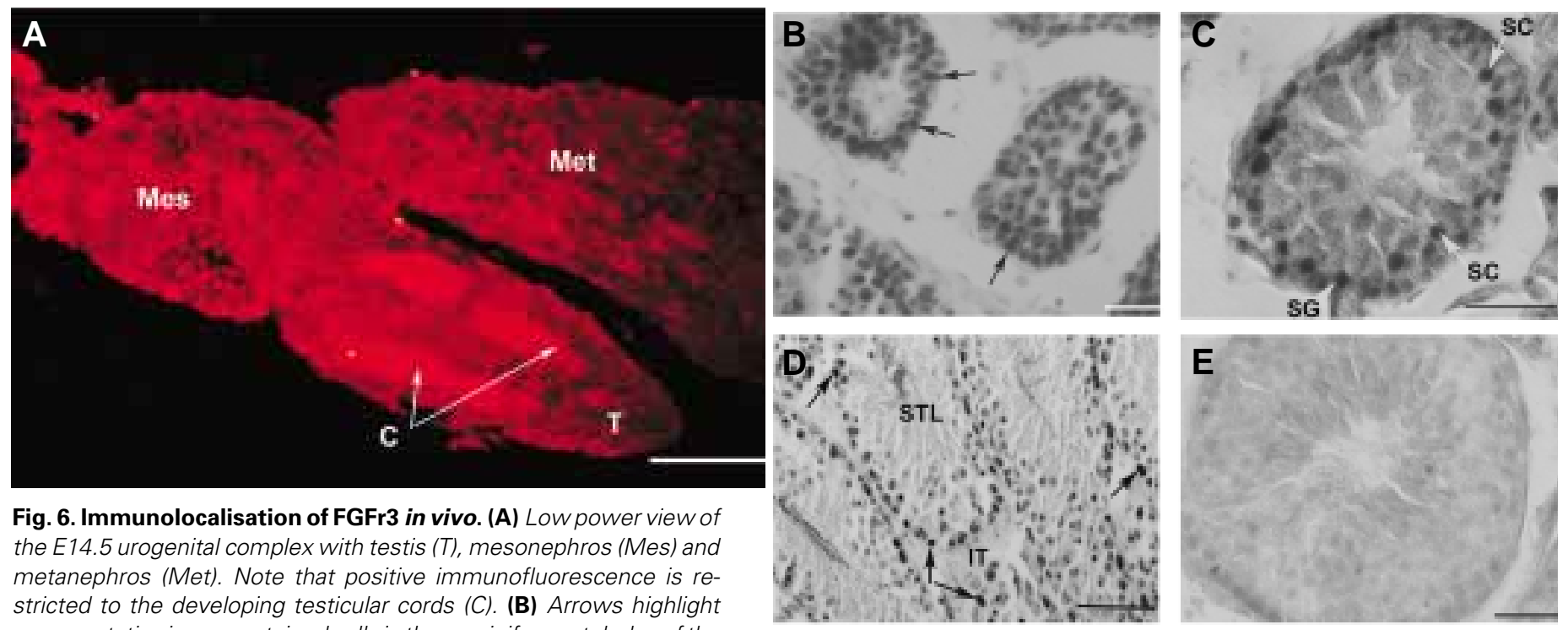

Fig. 6. Immunolocalisation of FGFr3 in vivo. (A) Low power view of the E14.5 urogenital complex with testis (T), mesonephros (Mes) and metanephros (Met). Note that positive immunofluorescence is restricted to the developing testicular cords (C). (B) Arrows highlight representative immunostained cells in the seminiferous tubules of the postnatal day 15 testis. (C) Sertoli cells (SC) and spermatogonia (SG) are both positively stained at postnatal day 25. (D) In the adult testis, staining is confined to spermatogonia (arrows) with absence of any staining in the interstitial tissue (IT) or in the lumen of the seminiferous tubule (STL). (E) Staining control of adult testis with primary antibody omitted. Bars, $100 \mu \mathrm{m}$ (A), $20 \mu \mathrm{m}$ (B,C and E), $50 \mu \mathrm{m}$ (D).

et al., 2003). It is unclear however, whether this increased expression applies to both the cytoplasmic and nuclear isoforms of the receptor and quantitative analysis is required to clarify this.

Immunolocalisation of FGFr3 in testes in vivo has a temporal pattern of expression. In the E14.5 urogenital complex, it is localised to Sertoli and germ cells in the newly formed testicular cords, but absent from the interstitial tissue. The mesonephros and metanephros are also negative. This specific localisation of FGFr3 supports the idea that FGF9 can influence developing Sertoli cells in vivo. In the pre-pubertal day 15 testis, receptor expression is abundant in most of the cells within the seminiferous tubules reflecting much mitotic activity occurring at this time. By puberty, FGFr3 immunostaining is generally localised in spermatagonia and Sertoli cells closest to the basement membrane of the tubule. Receptor expression is restricted in the adult to the spermatogonia which remain mitotically active.

In future studies, effects of FGF9 on whole gonad explants will be investigated and the functional status of the developing Sertoli cells will be determined by molecular methods. However, the present study, using our in vitroapproach, provides evidence of the role of FGF9 in embryonic testis development, especially in early proliferation.

\section{Materials and Methods}

\section{Animals}

CBA mice maintained on a reversed lighting regime were used for matings and the presence of a vaginal plug was designated day 0 of pregnancy. The total number of pregnant females used for culture experiments was 20 (i.e. usually 1-2 per experiment, yielding 7-10 pups per litter). Pregnant females were $\mathrm{CO}_{2}$ asphyxiated at 14.5 days post coitum (day of finding a plug = day 0 post coitum) and embryos were dissected from uterine horns and transferred to Hanks buffer (Gibco). The developmental stage of each embryo was determined according to Theiler (1972). Testes were identified by their larger size and striped appearance due to early vascularisation and cord development (Fig. 1A), whilst ovaries were smaller with a granular appearance (Fig. 1B). Once the urogenital complex was removed from the embryo, the attached mesonephros was separated and the testes from each individual were transferred to different Eppendorf tubes containing Hanks buffer, so that the control and experimental cultures contained tissue from the same individuals, thus reducing variation.

\section{Cell culture}

Embryonic Sertoli cells were isolated from E14.5 testes using a modification (Mackay et al., 1999) of the method of Chapin and coworkers (1987). This stage was chosen as a compromise between developmental state and size of testis, so that a sufficient number of developing Sertoli cells could be obtained. Briefly, the embryonic testes were subjected to enzymatic treatment at $37^{\circ} \mathrm{C}$ with $0.25 \%$ collagenase and $0.025 \%$ trypsin in Hanks buffer, each for 10 mins. The enzymatic digestion was stopped by transfer to Dulbecco's modification of Eagle's medium (DMEM) supplemented with $10 \%$ fetal calf serum and $0.1 \%$ gentamycin. Tissue was then disrupted further by mechanically tearing with Microlance needles and aspirating 10 times. Finally, the suspensions were transferred to microcentrifuge tubes and subjected to a series of centrifugations at $1000-4000 \mathrm{rpm}$ for $1 \mathrm{~min}$ each in a Microcentaur. The supernatant was removed from each control and experimental preparations and replaced with fresh Dulbecco's modified Eagles medium (PAA Laboratories, Austria, cat. no. E15-806) supplemented with $10 \%$ fetal calf serum and $1 \%$ gentamicin sulphate (ICN Biomedicals Inc.). After each spin the pellet was re-suspended. This method produces a gradual separation of Sertoli cells with germ cells, peritubular and Leydig cells lost in successive supernatants. Finally cells were plated out into Nunclon multiwell dishes at equal plating densities $\left(5 \times 10^{5} \mathrm{cells} / \mathrm{ml}\right)$ with viability estimated at $80-90 \%$ by Trypan Blue exclusion (Smith 1984). The wells were either coated with ECM gel (Sigma Aldrich cat. no. E1270) or left uncoated and in experimental wells DMEM was supplemented with $10 \mathrm{ng} /$ ml FGF9 (Sigma Aldrich cat. no. F1168) which, in pilot studies, was found to be effective. In order to monitor cell types separated throughout the isolation steps, supernatants were cultured for 4 days in DMEM and screened for specific markers.

All cultures were incubated at $37^{\circ} \mathrm{C}$ in $5 \% \mathrm{CO}_{2} / 95 \%$ air for $3-7$ days. Medium was changed every 48 hours and cultures monitored by daily 
phase contrast microscopy. Culture experiments were repeated at least ten times for proliferation studies and receptor localisation assessed for at least 4 experiments with all culture conditions.

\section{Immunocytochemistry}

At the end of the culture period cells were fixed in $4 \%$ paraformaldehyde for immunocytochemistry (ICC), using the following antibodies purchased from Santa Cruz Biotechnology, Inc. UK: FGFr3 (cat. no. sc-123), AntiMüllerian Hormone (AMH) (cat. no. sc-6886) and proliferating cell nuclear antigen (PCNA) (cat. no. sc-56). AMH was used both as a Sertoli cellspecific marker and also to assess functional status of the cells (Mackay et al., 2004), PCNA as a proliferative marker and FGFr3 as the receptor for FGF9. Smooth muscle $\alpha$-actin antibody, a known smooth muscle specific marker (Skalli et al., 1986), was purchased from Sigma Aldrich (cat.no. A2547) and used to identify peritubular cells in the cultured supernatants.

In initial pilot experiments, a range of antibody dilutions was evaluated: 1 in 200 proved to be the optimal dilution for FGFr3, 1 in 100 for PCNA and smooth muscle $\alpha$-actin and 1 in 50 for AMH. All antibodies were diluted with $0.3 \%$ Triton in phosphate buffered saline (PBS) containing $1 \%$ normal goat serum. This was incubated at $4^{\circ} \mathrm{C}$ overnight, followed by two washes in phosphate buffered saline (PBS). Secondary antibodies: anti-goat (AMH), anti-mouse (PCNA and smooth muscle $\alpha$ actin) and anti-rabbit (FGFr3) were then added (1/100) for one hour. Binding was visualised by either the avidin-biotin/DAB method (reviewed by Beck 1998), (Vectastain, Vector laboratories Ltd, Peterborough, UK) for PCNA and FGFr3 or by fluorescence detection (AMH, smooth muscle actin). Negative controls, omitting the primary antibody, were included for each.

Proliferating cell nuclear antigen (PCNA) is a protein which is commonly used as a mitotic marker (Kurki et al., 1988). Positive cells were counted and expressed as a mean percentage of the total cells for control and all experimental cultures in eight $450 \mu \mathrm{m}^{2}$ fields per well in 4 repeat experiments. Statistical analysis was performed using analysis of variance and the Kruskall Wallis test with post hoc analysis.

\section{In vivo}

Testes were removed from mice of selected ages: embryonic (E14.5), pre-pubertal (day 15), pubertal (day 25) and adult (3 months of age). They were fixed in $4 \%$ paraformaldehyde and wax embedded. Sections were cut at $7 \mu \mathrm{m}$ and mounted onto 3-Aminopropyltriethoxysilane (APES) coated slides. Immunocytochemistry was performed using FGFr3 antibody and methods as described above.

\section{Acknowledgements}

We are grateful to the Wellcome Trust for their financial support (Grant number 067482) and to Miss Ria D'Mello and Miss Frances McKee for their technical assistance.

\section{References}

ADAMS, I.R. and MCLAREN, A. (2002). Sexually dimorphic development of mouse primordial germ cells: switching from oogenesis to spermatogenesis. Development 129: 1155-1164.

BECK, S. (1998). Histology Kits: Avidin and Biotin Team Up to Tackle the Tissue. The Scientist 12: 16.

BRENNAN, J., TILMANN, C. and CAPEL, B. (2003). Pdgf- $\alpha$ mediates testis cord organization and fetal Leydig cell development in the XY gonad. Genes Dev. 17: 800-810.

BUEHR, M., GU, S. and MCLAREN, A. (1993). Mesonephric contribution to testis differentiation in the fetal mouse. Development 117: 273-281.

BURGESS, W.H. AND MACIAG, T. (1989). The heparin-binding (fibroblast) growth factor family of proteins. Annu. Rev. Biochem 58: 575-606.

CHAPIN, R.E., PHELPS, J.L., MILLER, B.E. and GRAY, T.J.B. (1987). Alkaline phosphatase histochemistry discriminates peritubular cells in primary rat testicular culture. J. Androl. 8: 155-161.
COHEN, R.I. and CHANDROSS K.J. (2000). Fibroblast growth factor-9 modulates the expression of myelin related proteins and multiple fibroblast growth factor receptors in developing oligodendrocytes. J. Neurosci. Res. 61: 273-87.

COLVIN, J. GREEN, R.P., SCHMAHL, J., CAPEL, B. and ORNITZ, D. (2001). Maleto-female sex reversal in mice lacking fibroblast growth factor 9. Ce//104: 87589.

CRUMLEY, G., BELLOT, F., KAPLOW, J.M., SCHLESSINGER, J., JAYE, M. AND DIONNE, C.A. (1991). High-affinity binding and activation of a truncated FGF receptor by both aFGF and bFGF. Oncogene 6: 2255-2262.

CUPP A.S., UZUMCU, M. and SKINNER M.K. (2003). Chemotactic role of neurotropin 3 in the embryonic testis that facilitates male sex determination. Biol. Reprod.68: 2033-2037.

GIANCOTTI, F.C. and RUOSLAHTI, E (1999). Integrin Signaling, Science 285: 1028-1033.

GNESSI, L., EMIDI, A., JANNINI, E.A., CAROSA, E., MARODER, M., ARIZZI, M., ULISSE, S. and SPERA, G. (1995). Testicular development involves the spatiotemporal control of PDGFs and PDGF receptors gene expression and action. J. Cell Biol. 131: 1105-1121.

HU, J., SHIMA, H. and NAKAGAWA, H. (1999). Glial cell line-derived neurotropic factor stimulates Sertoli cell proliferation in the early postnatal period of rat testis development. Endocrinology 140: 3416-3421.

JOHNSTON, C.L., COX, H.C., GOMM, J.J. and COOMBES, R.C. (1995). Fibroblast Growth Factor Receptors (FGFRs) Localise in different cellular compartments. J. Biol. Chem. 270: 30643-50.

KURKI, P. OGATA, K. and TAN, EM. (1988). Monoclonal antibodies to proliferating cell nuclear antigen (PCNA)/cyclin as probes for proliferating cells by immunofluorescence microscopy and flow cytometry. J. Immunol. Meth. 109: 49-59.

LEVINE, E., CUPP, A. S. and SKINNER, M. K. (2000). Role of neurotropins in rat embryonic testis morphogenesis (cord formation). Biol. Reprod. 62: 132-142.

MACKAY, S. (2000). Gonadal development in mammals at the cellular and molecular levels. Int. Rev. Cytol. 200: 47-99.

MACKAY, S., BOOTH, S.H, MACGOWAN, A. and SMITH R.A. (1999). Ultrastructural studies deomonstrate that epithelial polarity is established in cultured mouse pre-Sertoli cells by extracellular matrix components. J. Electron Microsc. 48: 159-165.

MACKAY, S., WILLERTON, L., BALLINGALL, C.L., HENDERSON, N.J.S. and SMITH, R.A. (2004). Developing mouse Sertoli cells in vitro: effects on developing ovaries in co-culture and production of AMH. Cells Tiss. Org. 177: 79-86.

ORTH, J.M., GUNSALUS, G.M. and LAMPERTI, A.A. (1988). Evidence from Sertoli cell depleted rats indicates that spermatid numbers in adults depends on numbers of Sertoli cells produced during perinatal development. Endocrinology 122: 787-794.

PELLINIEMI, L.J., FRÖJDMAN, K. and PARANKO, J. (1993). Embryological and prenatal development and function of Sertoli cells. In The Sertoli Cell (L.D. Russell and M.D. Griswald Eds.) pp87-113, Cache River press, Clearwater, IL.

SCHMAHL, J. and CAPEL, B. (2003). Cell proliferation is necessary for the determination of male fate in the gonad. Dev. Biol. 258: 264-276.

SCHMAHL, J., EICHER, E. M., WASHBURN, L. L. and CAPEL, B. (2000). Sry induces cell proliferation in the mouse gonad. Development 127: 65-73.

SCOTET, E. and HOUSSAINT, E. (1995). The choice between alternative IIlb and Illc exons of the FGFR-3 gene is not strictly tissue-specific. Biochim. Biophys. Acta 1264: 238-242.

SHARPE, R.M. (1994). Regulation of spermatogenesis. In The Physiology of Reproduction $2^{\text {nd }}$ Edn. Pp1363-1434. Eds E. Knobil and JD Neill. Raven Press, New York.

SHARPE, R.M. (1999). Fetal / neonatal hormones and reproductive function of the male in adulthood. In Fetal Programming: Influences on development and disease in later life. pp187-194.

SHARPE, R.M., MCKINNELL, C., KIVLIN, C. and FISHER, J.S. (2003). Proliferation and functional maturation of Sertoli cells and their relevance to disorders of testes function in adulthood. Reproduction 125: 769-784.

SKALLI, O., ROPRAZ, P., TRZECIAK, A., BENZONANA, G., GILLESSEN, D. and GABBIANI, G. (1986). A monoclonal antibody against alpha-smooth muscle actin: a new probe for smooth muscle differentiation. J. Cell Biol. 103: 27872796. 
SKINNER, M.K., TUNG, P. and FRITZ, I.B. (1985). Cooperativity between Sertoli cells and testicular peritubular cells in the production and deposition of extracellular matrix components. J. Cell Biol. 100: 1941-1947.

SMITH, R.A. (1984). Morphological changes in rat hepatocytes in primary cultures induced by Misonidazole, desmethylmisonidazole and Ro 03-8799. Virchows Arch (Cell Pathol.) B, 46: 65-76.

SWAIN, A. and LOVELL-BADGE, R. (1999). Mammalian sex determination: a molecular drama. Genes Dev. 13: 755-767.

THEILER, K. (1972). The House Mouse. Development and Normal Stages from Fertilization to Four Weeks of Age. Berlin, Heidelberg, New York: SpringerVerlag.

TUNG, P.S. and FRITZ, I.B. (1980). Interactions of Sertoli cells with myoid cells in vitro. Biol. Reprod. 23: 207-217.
UZUMCU, M., DIRKS, K.A. and SKINNER, M.K. (2002). Inhibition of plateletderived growth factor actions in the embryonic testis influences normal cord development and morphology. Biol. Reprod. 66: 745-753.

YAMANE, K, IHN H AND TAMAKI, K. (2003). Epidermal growth factor up-regulates expression of transforming growth factor beta receptor type II in human dermal fibroblasts by phosphoinositide 3-kinase/Akt signaling pathway: Resistance to epidermal growth factor stimulation in scleroderma fibroblasts. Arthritis Rheum 6: $1652-66$.

Received: December 2003

Reviewed by Referees: February 2004

Modified by Authors and Accepted for Publication: June and August 2004 